\title{
COMÉRCIO AMBULANTE:
}

\section{QUALIDADE MICROBIOLÓGICA DE CARNE ASSADA E CONHECIMENTO SOBRE AS BOAS PRÁTICAS DE MANIPULAÇÃO}

\section{Luís Antônio Dantas Silva, Caroline Bailona Lira e Keili Maria Cardoso de Souza ${ }^{1}$}

\section{RESUMO}

O comércio de alimentos praticado por ambulantes tem aumentado nos últimos anos no Brasil, porém questiona-se a segurança alimentar desses produtos. Considerando-se o elevado consumo de carne assada nas ruas de várias cidades do País, objetivou-se, nesta pesquisa, analisar a qualidade microbiológica da carne assada (bovina) e das mãos dos manipuladores deste produto no comércio ambulante na cidade de Anápolis-GO. Pretendeu-se, também, verificar o conhecimento sobre Boas Práticas pelos comerciantes. Foram avaliados 11 pontos de venda ambulante, coletando-se uma amostra de carne bovina crua e outra de carne assada. Em cada ponto, coletou-se também uma amostra das mãos do manipulador da carne assada por meio do enxágue das mãos em solução salina contida em saco plástico esterilizado. Além disso, foram aplicados questionários para verificar o conhecimento desses comerciantes sobre as normas de manipulação de alimentos. Nas amostras de carne crua, realizou-se a contagem de Escherichia coli e a pesquisa de Salmonella sp.; nas amostras de carne assada, a contagem de Staphylococcus aureus, E. coli e clostrídios sulfito-redutores e a pesquisa de Salmonella sp. Nas amostras das mãos, realizou-se a contagem de Staphylococcus aureus e Escherichia coli. A qualidade microbiológica mostrou-se satisfatória em 90,9\% (10/11) das amostras de carne assada. Nenhum dos manipuladores apresentou $S$. aureus ou E. coli nas mãos. Em relação ao conhecimento das normas de manipulação, as principais falhas identificadas referiam-se ao preparo e transporte de alimentos.

DESCRITORES: Alimentos de rua; manipulação de alimentos; doenças transmitidas por alimentos.

1 Curso de Farmácia, Centro Universitário de Anápolis-UniEVANGÉLICA, Anápolis, GO, Brasil.

Endereço para correspondência: Profa. Dra. Keili Maria Cardoso de Souza. Curso de Farmácia. UniEvangélica. Av. Universitária Km. 3,5, Cidade Universitária, CEP 75083-515, Anápolis, GO, Brasil. E-mail: keilisouza@yahoo.com

Recebido para publicação em: 21/7/2013. Revisto em: 1/4/2014. Aceito em: 23/6/2014. 


\begin{abstract}
Street food vendors: microbiological quality of barbecued meat and knowledge of good food preparation practices

The food trade by street vendors in Brazil has increased in recent years, but there are questions about the food safety of these products. In view of the high consumption at street barbecues in cities across the country, this study aimed to analyze the microbiological quality of barbecued meat sold by street vendors, while testing the adoption of good food preparation practices by the food handlers in the city of Anápolis, Goiás. Eleven points of sale were evaluated and at each point samples of raw and cooked meat were collected. The cleanliness of sellers' hands was also evaluated through the collection of samples by the rinsing of their hands in saline contained in a sterile plastic bag. Questionnaires were applied to check the knowledge of vendors about food safety practices. Samples of raw meat were checked for Escherichia coli and Salmonella spp., while the samples of cooked beef were checked for Staphylococcus aureus, E. coli, sulphite reducing Clostridium and Salmonella spp., as required by the legislation. The microbiological analysis revealed that one stall had cooked meat of an unsatisfactory quality. None of the handlers had $S$. aureus or E. coli on their hands. Regarding the knowledge of good practices, failures were noted, mainly in the preparation and transport of food.
\end{abstract}

KEY WORDS: Street food; food handling; food borne diseases.

\title{
INTRODUÇÃO
}

A cada ano cresce o emprego informal nos municípios brasileiros. Dentro deste contexto, observa-se o aumento do número de vendedores ambulantes nas cidades, seja apenas comercializando ou também preparando alimentos (17).

Trata-se de uma atividade informal, com produtos de rápido preparo, baixo custo e comercializados em locais de fácil acesso, como ruas, centrais e terminais de ônibus, praças e similares. Porém, o risco de uma contaminação alimentar é elevado, visto que o processamento é realizado de forma artesanal, sem controles específicos, sem infraestrutura adequada e sem os conhecimentos necessários sobre a manipulação segura de alimentos $(13,17)$.

No Brasil, estudos realizados com alimentos comercializados por ambulantes em diversas regiões demonstraram que este tipo de produto pode representar um risco para a saúde pública $(4,7,13,15,20)$.

É grande a responsabilidade que deve ser atribuída à manutenção da higiene nos estabelecimentos transformadores ou beneficiadores de produtos de origem animal, pois são eles os que mais preocupam as autoridades sanitárias, em virtude da perecibilidade dos produtos e dos riscos que representam para os consumidores (12).

Neste tipo de comércio, os alimentos podem ser facilmente contaminados com micro-organismos patogênicos quando são inadequadas as condições do local de preparo e falta o conhecimento das Boas Práticas de Manipulação de alimentos por parte dos comerciantes (13). 
Embora seja elevado o consumo de carne assada vendida por ambulantes pela população, existe pouca informação sobre sua qualidade higiênica e o potencial risco para os consumidores que esses alimentos representam (5). Por isso, com este estudo, pretendeu-se avaliar a qualidade microbiológica tanto das mãos dos manipuladores quanto quanto da carne assada bovina e verificar a adoção das Boas Práticas de Manipulação no comércio ambulante deste produto na cidade de Anápolis-Goiás.

\section{MATERIAL E MÉTODOS}

Coleta de amostras

Após a aprovação do projeto de pesquisa pelo Comitê de Ética em Pesquisa do Centro Universitário de Anápolis (Protocolo no 0096/2009) e pela Gerência de Vigilância Sanitária Municipal (VISA), teve início a coleta das amostras em diferentes pontos da cidade, acompanhando-se a rota de inspeção da equipe noturna da VISA. Após serem abordados e esclarecidos sobre a pesquisa, os vendedores ambulantes e manipuladores de carne assada assinaram o Termo de Consentimento Livre e Esclarecido (TCLE), doaram as amostras (uma de carne bovina crua e outra assada) e responderam a um questionário sobre aquisição, manipulação, transporte e armazenamento do produto.

Foram avaliados 11 pontos de venda ambulante de carne assada bovina nos meses de março e abril de 2010, na cidade de Anápolis-Goiás. Os pontos avaliados foram escolhidos aleatoriamente em seis diferentes bairros da cidade: Centro, Vila Miguel Jorge, Santa Maria, Parque São João, Jardim das Américas I etapa e Jaiara. Em dois bairros, foram sete os pontos de venda avaliados (quatro no bairro Vila Miguel Jorge e três no Centro), em virtude do grande fluxo de pessoas ali existente. Nos outros bairros, apenas um ponto de venda foi avaliado.

Em cada ponto, foram coletadas duas amostras de carne bovina, uma crua e outra assada (amostragem indicativa), armazenadas em sacos esterilizados. Foram realizadas também coletas de amostras das mãos de um manipulador de cada ponto de venda. Esta última foi realizada de acordo com a técnica de Germano (2007), por meio da lavagem das duas mãos de cada manipulador com $200 \mathrm{~mL}$ de solução salina, solução esta que foi acondicionada em saco plástico esterilizado.

As amostras foram transportadas em temperatura de $2^{\circ}$ a $8^{\circ} \mathrm{C}$ no prazo de até 12 horas para o Laboratório de Microbiologia do Centro Universitário de Anápolis-UniEvangélica para realização das análises.

Parâmetros analisados

Amostras de carne

A pesquisa foi realizada conforme os parâmetros da Resolução de Diretoria Colegiada (RDC) da Agência Nacional de Vigilância Sanitária (ANVISA) 
$\mathrm{n}^{\mathrm{o}} 12$ de 2001 (2). Na carne bovina crua, a legislação determina contagem de E. coli e pesquisa de Salmonella sp. e na carne bovina assada, contagem de $S$. aureus, E. coli, Clostridium sulfito redutor e B. cereus e pesquisa de Salmonella sp. Não foi possível realizar a contagem de $B$. cereus nesta pesquisa, pois não havia disponibilidade dos meios e tampouco dos reagentes no laboratório. Os protocolos de análise foram realizados de acordo com Silva et al. (2007). Todas as análises foram efetuadas em duplicata.

De cada amostra foram coletados $25 \mathrm{~g}$, seguindo-se a homogeneização em $225 \mathrm{~mL}$ de água peptonada (diluição $10^{-1}$ ) para quantificação de $S$. aureus, E. coli $\mathrm{e}$ Clostridium. Para estas análises, foram preparadas também as diluições $10^{-2}$ e $10^{-3}$ em água peptonada. Para o pré-enriquecimento de Salmonella sp, outra porção de $25 \mathrm{~g}$ foi homogeneizada em água peptonada tamponada.

- Escherichia coli: foi aplicada a técnica de tubos múltiplos, utilizando-se o caldo EC com incubação a $45,5^{\circ} \mathrm{C}$ por 24 horas. Nos tubos em que foi observada a turvação e a formação de gás, buscou-se a confirmação da espécie $E$. coli utilizando o ágar Eosina Azul de Metileno (EMB) e provas bioquímicas (Indol, Vermelho de Metila, Voges Proskauer e Citrato).

- Contagem de Staphylococcus aureus: utilizou-se a técnica de inoculação em superfície em ágar Baird Parker, acrescido de solução de telurito de potássio a $1 \%$ e emulsão de gema de ovo a $50 \%$ em solução salina com incubação a $35^{\circ} \mathrm{C}$ por 48 horas. As colônias características, negras com halo claro, foram identificadas por provas bioquímicas (catalase, coagulase e DNAse).

- Contagem de Clostrídios sulfito-redutores a $46^{\circ} \mathrm{C}$ : utilizou-se o ágar Sulfito Polimixina Sulfadiazina (SPS) com incubação a $46^{\circ} \mathrm{C}$ por 24 horas em jarra de anaerobiose.

- Pesquisa de Salmonella sp.: após pré-enriquecimento em água peptonada tamponada a $35^{\circ} \mathrm{C}$ por 24 horas, transferiu-se $0,1 \mathrm{~mL}$ para o caldo Rappaport. Após incubação a $35^{\circ} \mathrm{C}$ por 24 horas, foi realizada a semeadura em ágar Xilose Lisina Desoxicolato (XLD), ágar Verde Brilhante e ágar entérico de Hektoen. As colônias típicas em cada meio foram submetidas a provas bioquímicas: Fermentação de Glicose, Lactose, Manitol, Sorbitol e Maltose, Vermelho de Metila, Produção de $\mathrm{H}_{2} \mathrm{~S}$, Indol, Acetoína (Voges Proskauer), Urease, Utilização de Citrato, Malonato, Desaminação da Fenilalanina, Descarboxilação da Lisina, Ornitina, Arginina e Motilidade.

Amostras das mãos

As técnicas utilizadas seguiram os protocolos estabelecidos por Sveum et al. (1992), substituindo-se o agar Baird-Parker por agar Manitol Salgado. As análises foram realizadas em duplicata e nas diluições $10^{-1}, 10^{-2}$ e $10^{-3}$.

- Pesquisa de Staphylococcus aureus: utilizou-se o ágar Manitol Salgado, seguindo-se a técnica de semeadura em superfície com inóculo de $0,1 \mathrm{~mL}$ da amostra 
e incubação a $35^{\circ} \mathrm{C}$ por $24-48$ horas. As colônias amarelas foram submetidas às provas da catalase, coagulase e DNase.

- Pesquisa de Escherichia coli: utilizou-se o ágar EMB, seguindo-se também a técnica de semeadura em superfície e incubação a $35^{\circ} \mathrm{C}$ por $24-48$ horas. Como não houve crescimento de colônias escuras, típicas de $E$. coli neste meio, não foram realizados os testes bioquímicos de identificação.

Questionário sobre Boas Práticas de Manipulação

O questionário com perguntas abertas e fechadas sobre as Boas Práticas de Manipulação foi elaborado com base na RDC (ANVISA) 216/2004 (3), sendo aplicado aos manipuladores presentes no ponto de venda no momento da coleta de amostras.

\section{RESULTADOS}

$\mathrm{Na}$ presente pesquisa, das 11 amostras de carne crua analisadas, 9 apresentaram $E$. coli em diferentes níveis, entretanto nenhuma delas estava acima do preconizado $\left(10^{4}\right)$ pela legislação (Tabela 1). Em uma das amostras (ponto 5), houve contagem maior que $2,4 \times 10^{3} \mathrm{NMP} / \mathrm{g}$. Não foi observada a presença de Salmonella sp. em nenhuma das amostras de carne crua analisadas.

Tabela 1. Parâmetros microbiológicos analisados nas amostras de carne bovina crua comercializadas por ambulantes, no período de março e abril de 2010, na cidade de Anápolis, GO.

\begin{tabular}{ccc}
\hline \multirow{2}{*}{ Pontos de Coletas } & \multicolumn{2}{c}{ Parâmetros analisados } \\
\cline { 2 - 3 } & Escherichia coli $(\mathrm{NMP} / \mathrm{g})$ & Salmonella $\mathrm{sp} / 25 \mathrm{~g}$ \\
\hline Ponto 1 & $1,1 \times 10$ & Ausente \\
\hline Ponto 2 & $2,0 \times 10$ & Ausente \\
\hline Ponto 3 & 7,2 & Ausente \\
\hline Ponto 4 & 7,2 & Ausente \\
\hline Ponto 5 & $>2,4 \times 10^{3}$ & Ausente \\
\hline Ponto 6 & $4,6 \times 10^{2}$ & Ausente \\
\hline Ponto 7 & $2,3 \times 10$ & Ausente \\
\hline Ponto 8 & $<3$ & Ausente \\
\hline Ponto 9 & $4,3 \times 10$ & Ausente \\
\hline Ponto 10 & $2,3 \times 10$ & Ausente \\
\hline Ponto 11 & $<3$ & Ausente \\
\hline Tolerância para amostra indicativa* & $10^{4}$ & Ausente \\
\hline
\end{tabular}

*Segundo RDC (ANVISA) No 12 de janeiro de 2001 - Regulamento Técnico Sobre Padrões Microbiológicos Para Alimentos (item 5e); NMP/g - Número Mais Provável por grama.

Das 11 amostras Das 11 amostras de carne assada, 2 (pontos 5 e 6) apresentaram E. coli, tendo a amostra do ponto 5 apresentado contagem superior 
ao permitido pela resolução $(2$ x $10 \mathrm{NMP} / \mathrm{g})$, conforme demonstra a Tabela 2 . Nestas 11 amostras, não houve presença de Clostrídios sulfito-redutores, S.aureus e Salmonella sp.

Tabela 2. Parâmetros microbiológicos analisados em amostras de carne bovina assada comercializadas por ambulantes, no período de março e abril de 2010, na cidade de Anápolis, GO.

\begin{tabular}{ccccc}
\hline & \multicolumn{4}{c}{ Parâmetros analisados } \\
\cline { 2 - 5 } Pontos de Coletas & $\begin{array}{c}\text { Escherichia } \\
\text { coli } \\
(\mathrm{NMP} / \mathrm{g})\end{array}$ & $\begin{array}{c}\text { Clostrídios } \\
\text { Sulfito } \\
\text { Redutores a } \\
46^{\circ} \mathrm{C}(\mathrm{UFC} / \mathrm{g})\end{array}$ & $\begin{array}{c}\text { Staphylococcus } \\
\text { aureus } \\
(\mathrm{UFC} / \mathrm{g})\end{array}$ & $\begin{array}{c}\text { Salmonella } \\
\mathrm{sp} / 25 \mathrm{~g}\end{array}$ \\
\hline Ponto 1 & $<3$ & $<10$ & $<10$ & Ausente \\
\hline Ponto 2 & $<3$ & $<10$ & $<10$ & Ausente \\
\hline Ponto 3 & $<3$ & $<10$ & $<10$ & Ausente \\
\hline Ponto 4 & $<3$ & $<10$ & $<10$ & Ausente \\
\hline Ponto 5 & $2,3 \mathrm{x} 10$ & $<10$ & $<10$ & Ausente \\
\hline Ponto 6 & 9,2 & $<10$ & $<10$ & Ausente \\
\hline Ponto 7 & $<3$ & $<10$ & $<10$ & Ausente \\
\hline Ponto 8 & $<3$ & $<10$ & $<10$ & Ausente \\
\hline Ponto 9 & $<3$ & $<10$ & $<10$ & Ausente \\
\hline Ponto 10 & $<3$ & $<10$ & $<10$ & Ausente \\
\hline Ponto 11 & $<3$ & $<10$ & $<10$ & Ausente \\
\hline Tolerância para amostra indicativa* & $2 \times 10$ & $10^{3}$ & $10^{3}$ & Ausente \\
\hline
\end{tabular}

*Segundo Resolução RDC 12 de janeiro de 2001 - Regulamento Técnico Sobre Padrões Microbiológicos Para Alimentos (item 22a). NMP/g - Número Mais Provável por Grama. UFC/g - Unidade Formadora de Colônia por Grama.

Quanto à qualidade microbiológica das mãos dos manipuladores, não foram identificados $S$. aureus e $E$. coli em nenhuma das amostras, constatando-se condições higiênicas satisfatórias.

Com relação ao questionário sobre o conhecimento de Boas Práticas aplicado aos participantes da pesquisa, oito vendedores $(72,7 \%)$ relataram preparar relataram preparar a carne para assar, entre os quais a maioria $(87,0 \%)$ declarou não fazer uso de proteção para os cabelos e $12,5 \%$ utilizar bancada de material não apropriado (suporte de madeira) para a manipulação.

A carne crua e preparada para assar é transportada congelada até o local da venda: quatro comerciantes (36,4\%) transportam em caixa de isopor e, destes, três utilizam gelo (não reciclável) no transporte; dois $(18,2 \%)$ transportam em sacos plásticos, dois $(18,2 \%)$ preparam preparam a carne em um local ao lado do ponto de venda e os demais utilizam caixa (um) ou fôrma de alumínio (um) ou caixa isotérmica (um). Todos mantêm a carne preparada para assar nos mesmos recipientes de transporte até o momento de assar.

Conforme declararam os comerciantes, o tempo gasto para assar a carne é, em média, de 14 minutos, com variação mínima e máxima de 5 a 30 minutos, 
respectivamente. Quando questionados se havia pedidos de carne mal passada, a maioria $(54,4 \%)$ declarou que há muitos pedidos, o que pode representar maior risco para os consumidores se a carne crua apresentar parâmetros microbiológicos acima do que determina a legislação.

Todos os vendedores relataram colocar no congelador a carne crua que não foi assada. Sobre a carne assada que sobra, oito entrevistados disseram que levam para casa para comer, dois jogam fora e um guarda para vender no dia seguinte.

Quanto à higienização dos utensílios, a maioria $(54,6 \%)$ não os lava todos os dias, sendo a água corrente (90,9\%), a esponja e o sabão líquido (63,6\%) os produtos mais utilizados na lavagem.

Com relação aos hábitos higiênicos dos manipuladores, todos eles afirmaram que lavam cuidadosamente as mãos depois do uso de sanitários e se afastam do alimento que estão manuseando ao tossir ou espirrar. A maioria relatou manter as unhas cortadas e limpas $(90,9 \%)$ e lavar as mãos depois de manusear lixo e sujeiras $(81,8 \%)$ e antes da manipulação de alimentos $(90,9 \%)$. Porém, muitos trabalham sem usar uniforme claro e limpo $(81,8 \%)$, com feridas no corpo $(63,6 \%)$ e manuseiam dinheiro enquanto estão manipulando a carne (54,5\%). Somente 54,5\% dos manipuladores relataram conhecer as exigências higiênico-sanitárias impostas à manipulação de alimentos, mas a maioria $(81,8 \%)$ afirmou ter consciência de que os alimentos podem transmitir doenças e causar até a morte. Todos foram unânimes em garantir que se preocupam com a qualidade e segurança do alimento que manipulam.

\section{DISCUSSÃO}

Identificou-se a presença de E. coli nas amostras de carne crua e assada do presente estudo sem, contudo, apresentar níveis comprometedores, exceto na amostra (assada) obtida do ponto 5. Na amostra crua, do mesmo ponto, não foi obtida a quantificação exata, pois seriam necessárias maiores diluições da amostra.

Em alguns estudos, evidenciou-se qualidade higiênico-sanitária insatisfatória em amostras de carne crua comercializada em diferentes tipos de comércio. Ludgren et al. (2009) avaliaram a carne bovina comercializada em feiras livres e mercados públicos de João Pessoa, Paraíba, e identificaram seis amostras contaminadas com E. coli, (60\%) e Staphylococcus coagulase positiva em oito amostras com contagem média de $2,7 \times 10^{5} \mathrm{UFC} / \mathrm{g}$ de dez amostras analisadas. Salmonella sp. não foi detectada nesse estudo. Em outra pesquisa sobre a carne bovina comercializada em supermercados (11) de João Pessoa, Paraíba, também houve a presença de E. coli em sete de dez amostras de carne crua, mas nenhuma delas estava acima do especificado. Staphylococcus coagulase positiva estava presente em todas as amostras, entretanto os valores estavam em conformidade com a legislação. Salmonella sp. não foi detectada. 
Com relação à avaliação microbiológica das mãos dos manipuladores, não se verificou, na presente pesquisa, contaminação por $E$. coli $\mathrm{e} S$. aureus. Nos estudos de Mesquita et al. (2006) também foi constatada ausência de Staphylococcus coagulase positiva nas mãos dos manipuladores de uma Unidade de Alimentação e Nutrição em Santa Maria, Rio Grande do Sul. Já Abreu et al. (2011) detectaram E. coli nas mãos de todos os manipuladores (12) do comércio ambulante de cachorroquente de Santo André-SP, sendo verificado que todos eles não lavavam as mãos durante o trabalho. Souza et al. (2007) verificaram que, dos 12 manipuladores de carne bovina analisados na feira livre de Bananeiras, Paraíba, 7 apresentaram $S$. aureus tanto nas mãos como nas cavidades nasais.

Buscando garantir a produção segura de alimentos, diversas exigências são estabelecidas pela legislação que trata das Boas Práticas para Serviços de Alimentação - RDC (ANVISA) n n 216/2004 (3). O conhecimento dos manipuladores de alimentos sobre tais exigências é fundamental para que eles não se tornem fator de contaminação alimentar. Nesta pesquisa, observou-se que os manipuladores desconhecem algumas normas, principalmente quanto ao preparo e conservação de alimentos.

Muitos manipuladores relataram preparar a carne sem a necessária paramentação, com utensílios inadequados, como as tábuas de madeira, e que transportam e conservam a carne em recipientes impróprios que não permitem a limpeza e/ou manutenção da temperatura. Muitos entrevistados relataram ainda que manuseiam dinheiro enquanto manipulam alimento e trabalham com ferimentos na pele. Todas essas práticas elevam os riscos de contaminação dos alimentos, pois o dinheiro e as feridas são importantes focos de disseminação de micro-organismos.

Segundo a legislação citada (3), os manipuladores devem ter asseio pessoal, usar uniformes, manter cabelos presos e protegidos por redes, toucas ou outro acessório apropriado para esse fim.

Segundo estudo de Rodrigues et al. (2010), 96,2\% dos manipuladores em pontos de venda ambulantes na cidade de Paraíso do Tocantins não usavam uniforme adequado, não demonstravam um asseio pessoal satisfatório (visto que exibiam adornos, esmalte nas unhas compridas e falta de boa apresentação corporal) e $87,5 \%$ manipulavam dinheiro com frequência.

Wormsbecker (2012) analisou 50 manipuladores de alimentos de rua na região central da cidade de Florianópolis, Santa Catarina, e verificou que $86 \%$ dos vendedores usavam jaleco e o mantinham limpo, mas 74\% usavam adornos e 92\% manipulavam dinheiro e alimentos sem lavar as mãos. Silva et al. (2011) observaram 24 pontos informais de venda de alimentos nas vias públicas no Câmpus do Porangabuçu da Universidade Federal do Ceará e verificaram que $66,6 \%$ dos vendedores usavam adornos durante a manipulação dos alimentos.

A legislação (3) estabelece que a manutenção de produtos em condições inadequadas, ou seja, fora de refrigeração, compromete a qualidade do produto final. Em pesquisa de Claudino \& Souza (2009), ficaram evidenciadas irregularidades 
no armazenamento de carnes comercializadas em barracas de uma feira em Caldas Novas, GO.

A higienização de utensílios é um item fundamental nas Boas Práticas, uma vez que, sendo inadequada, não irá eliminar os riscos microbiológicos. No comércio ambulante de Ponta Grossa, no Paraná (8), cerca de 60,0\% dos proprietários não fazem higienização constante dos utensílios, semelhantemente ao que foi observado na presente pesquisa. Silva et al. (2011) verificaram que havia sujeira visível nos utensílios em 37,5\% dos pontos de venda ambulante no Câmpus da Universidade Federal do Ceará.

Em relação à higiene das mãos, a maioria dos entrevistados afirmou adotar o cuidado básico de lavagem das mãos durante a rotina dos serviços. Este resultado é compatível com a análise microbiológica das mãos dos manipuladores.

A instituição de manual de Boas Práticas e a capacitação continuada estão entre as ações que mais contribuem para o cumprimento das exigências da legislação (14). Na pesquisa de Nicolau et al. (2014), houve uma considerável redução nos índices de contaminação de tortas doces comercializadas em 105 bancas nas 23 feiras especiais da cidade de Goiânia após a capacitação dos feirantes em Boas Práticas. No estudo de Ferreira et al. (2008) com espetinhos de frango fabricados no município de Uberlândia, também houve uma redução significativa do número de coliformes entre 2003 e 2004, em virtude da implementação das Boas Práticas de Fabricação nos estabelecimentos inspecionados.

Portanto, embora nesta pesquisa a qualidade higiênico-sanitária das amostras na maioria dos pontos esteja em conformidade com a legislação, recomenda-se a capacitação dos manipuladores deste produto no comércio ambulante com relação às Boas Práticas, uma vez que ficou evidenciado grande desconhecimento das exigências normativas.

\section{CONCLUSÕES}

Observou-se qualidade microbiológica satisfatória de carne assada) comercializada em 90,9\% (10) dos pontos de venda ambulante analisados nacidade de Anápolis-GO, assim como das mãos dos manipuladores, embora seja deficiente o conhecimento que eles têm sobre as Boas Práticas.

\section{REFERÊNCIAS}

1. Abreu ES, Medeiros FS, Santos DA. Análise microbiológica de mãos de manipuladores de alimentos do município de Santo André. Rev UNIVAP Online 17: 39-57, 2011. Disponível em: http://revista.univap.br/index.php/revistaunivap/article/view/24/24. Acesso em 17/07/2013

2. BRASIL. Agência Nacional de Vigilância Sanitária. Resolução da Diretoria Colegiada (RDC) No 12, de 2 de janeiro de 2001. Dispõe sobre o regulamento técnico sobre padrões microbiológicos para alimentos. Diário Oficial da República Federativa do Brasil, Brasília, 2001. p. 1-48 
3. BRASIL. Agência Nacional de Vigilância Sanitária. Resolução da Diretoria Colegiada (RDC) No 216, de 15 de setembro de 2004. Dispõe sobre o regulamento técnico de boas práticas para serviços de alimentação. Diário Oficial da República Federativa do Brasil, Brasília, 2004. p. 1-10.

4. Claudino DN, Souza PAB. A Qualidade dos alimentos comercializados na Feira do Luar (Caldas Novas- GO). Goiânia [Trabalho de Curso - UEG], 2009.

5. Ferreira IM, Bonnas DS, Rezende MTNP, Rossi DA. Bacteriologia de "espetinhos de frango" fabricados sob inspeção municipal no município de Uberlândia, MG. Vet Not 2: 119, 2008.

6. Germano MS. Segurança Alimentar: A arma pode estar em suas mãos. Rev Hig Aliment 21: 16-17, 2007.

7. Ludgren PU, Silva JA, Maciel JF, Fernandes TM. Perfil da qualidade higiênico-sanitária da carne bovina comercializada em feiras livres e mercados públicos de João Pessoa, PB-Brasil. Rev Aliment Nutr 20: 113-119, 2009.

8. Mallon C, Bortolozo EAFQ. Alimentos comercializados por ambulantes: uma questão de segurança alimentar. Publicatio UEPG Ciências Biológicas e da Saúde 10: 65-76, 2004.

9. Mesquita MO, Daniel AP, Saccol ALF, Milane LIG, Fries LLM. Qualidade microbiológica no processamento do frango assado em unidade de alimentação e nutrição. Ciênc Tecnol Aliment 26: 198-203, 2006.

10. Nicolau ES, Soares NR, Barros JC, Silva BS, Silva MAP, Cavalcante SO. Avaliação microbiológica de tortas doces comercializadas em feiras especiais da cidade de Goiânia-GO. Semina Ci Agr Londrina 35: 303-316, 2014.

11. Oliveira S, Silva JÁ, Maciel JF, Aquino JS. Avaliação das condições higiênico-sanitárias de carne bovina comercializada em supermercados de João Pessoa. Rev Aliment Nutr 19: 61-66, 2008.

12. Pardi MC, Santos JF, Sousa ER, Pardi HS. Ciência, Higiene e Tecnologia da Carne. CEGRAF. Goiânia, 2006. Volume I.

13. Rodrigues FM, Viroli SLM, Pavlik MCM, Sandi AAS. Avaliação das condições higiênicosanitárias do comércio ambulante de alimentos na cidade de Paraíso do Tocantins. Rev ACTA Tecnol 5: 100-112, 2010.

14. Silva LA. Avaliação do aprendizado dos manipuladores de alimentos antes e após a capacitação quanto a higiene pessoal. Salvador [Monografia de Especialização em Gestão da Qualidade Vigilância Sanitária de Alimentos-UFERSA], 2008.

15. Silva LIMM, Thé PMP, Farias GS, Thelmos BMA, Fiuza MP, Castelo Branco CC. Condições higiênico-sanitárias do comércio de alimentos em via pública em um campus universitário. Alim Nutr Araraquara 22: 89-95, 2011.

16. Silva N, Junqueira VCA, Silveira NFA, Taniwaki MH, Santos RFS, Gomes RAR. Manual de Métodos de Análise Microbiológica de Alimentos. Livraria Varela. São Paulo, 2007.

17. Soto FRM, Risseto MR, Lúcio D, Shimozako HJ, Camargo CC, Iwata MK, Camargo CA, Oliveira E, Camargo SR. Metodologia de avaliação das condições sanitárias de vendedores ambulantes de alimentos no município de Ibiúna-SP. Rev Bras Epidemiol 11: 297-303, 2008.

18. Souza JG, Costa FN, Alves LMC, Machado PP, Leite PRSC. Pesquisa de Estafilococos coagulase positiva em manipuladores de uma unidade de alimentação, na cidade de São Luís, MA. Rev Hig Aliment 21: 69-75, 2007.

19. Sveum, WH, Moberg LJ, Rude RA, Frank JF. Microbiological monitoring of the food-processing environment. In: Vanderzant C, Splittstoesser DF, Speck ML. Compendium of methods for the microbiological examination of foods. APHA. Washington, 1992.

20. Wormsbecker LMC. Alimentos de rua em Florianópolis: perfil do manipulador e características dos alimentos comercializados. Florianópolis [Dissertação de mestrado em Nutrição - UFSC], 2012. 